\title{
NUMERICAL SOLUTION OF THE DZEKTSER EQUATION WITH "WHITE NOISE" IN THE SPACE OF SMOOTH DIFFERENTIAL FORMS DEFINED ON A TORUS
}

\author{
D. E. Shafranov, South Ural State University, Chelyabinsk, Russian Federation, \\ shafranovde@susu.ru
}

\begin{abstract}
In this paper, we present numerical solutions to the Cauchy problem for the Dzektser equation in the non-deterministic case in the space of differential forms on a two-dimensional torus. Based on the solutions constructed earlier by the author for the deterministic case and, in collaboration with other authors, abstract transition for the case of relatively sectorial operators from deterministic Sobolev type equations to non-deterministic ones in the space of differential forms defined on Riemannian manifolds without boundary, we construct trajectories of the solution to the Cauchy problem for the Dzektser equation in the spaces of differential forms with coefficients that are Wiener stochastic processes. Since these processes are non-differentiable in the usual sense, then the derivative is taken in the sense of Nelson - Glicklikh, and the Laplace - Beltrami operator is used instead of the Laplace operator on differential forms.
\end{abstract}

Keywords: Sobolev type equations; relatively sectorial operator; differential forms; Nelson - Gliklikh derivative; Laplace - Beltrami operator.

\section{Introduction}

Let $\mathfrak{U}$ and $\mathfrak{F}$ be Banach spaces. The paper [1] investigates questions of the solvability of the Sobolev type equations with an irreversible operator in the derivative

$$
L \dot{u}=M u+f
$$

where the operator $L \in \mathcal{L}(\mathfrak{U} ; \mathfrak{F})$ belongs to the space of linear and bounded operators, and the operator $M \in C l(\mathfrak{U} ; \mathfrak{F})$ belongs to the space of closed densely defined operators in the case of the $(L, p)$-bounded or $(L, p)$-sectorial operator $M$. Based on this research, the paper [2] studies the equation of the free surface of the filtered fluid

$$
(\lambda-\Delta) u_{t}=\alpha \Delta u-\beta \Delta^{2} u
$$

with the $(L, 0)$-sectorial operator $M=\alpha \Delta-\beta \Delta^{2}$ and in the space of differential forms defined on $n$-dimensional smooth compact oriented manifold without boundary. The Cauchy problem

$$
u(0)=u_{0}
$$

for equation (2) has a phase space which contains the trajectories of all solutions for which the existence and uniqueness are proved. The paper [3] investigates the Showalter - Sidorov problem

$$
P\left(u(0)-u_{0}\right)=0
$$

for a stochastic abstract semilinear Sobolev type equation with the $(L, p)$-sectorial operator $M$ in the spaces of Wiener stochastic processes

$$
L \stackrel{\circ}{\eta}=M \eta+N(\Theta) \text {. }
$$


Since the Wiener processes are continuous but non-differentiable at each point in the usual sense, we use the derivative in the sense of Nelson - Gliklikh [4]. In this paper, we study numerical solutions to the Showalter - Sidorov problem for the equation of the free surface of a filtered fluid in the spaces of differential forms defined on a two-dimensional torus in the form $(3)$ in the case of an $(L, p)$-sectorial operator by analogy with the approach used to analyze the analytical solutions obtained in [5] by constructing a difference analogue and finding numerical solutions to the Barenblatt - Zheltov - Cochina equation with an $(L, p)$-bounded operator in $[6]$.

\section{Description of Spaces of Differentiable "Noises"}

Let $\Omega=(\Omega, \Sigma, P)$ be the complete probability space with the probability measure $P$ associated with the sigma-algebra $\Sigma$ of the subsets of the space $\Omega$. Let $\mathcal{R}$ be the set of real numbers endowed with a sigma algebra, then the map $\xi: \Sigma \mapsto \mathcal{R}$ is called a random variable. The set of random variables $\xi$ with zero mathematical expectation $M \xi=0$ and finite variance $D \xi<\infty$ forms the Hilbert space $\mathfrak{L}_{\mathbf{2}}$ with the scalar product $\left(\xi_{1}, \xi_{2}\right)=M \xi_{1} \xi_{2}$ and with the norm denoted by $\|\xi\|_{\mathfrak{L}_{2}}$. If we consider the subalgebra $\Sigma_{0}$ of the sigma-algebra $\Sigma$, then we obtain the subspace of random variables $\mathfrak{L}_{\mathbf{2}}^{\mathbf{0}} \subset \mathfrak{L}_{\mathbf{2}}$ measurable with respect to $\Sigma_{0}$

The measurable map $\eta=\eta(t, \omega): J \times \Sigma \mapsto \mathcal{R}$, where $J=(a, b) \subset \mathcal{R}$ is a certain interval, is called a stochastic process, the random variable $\eta(\cdot, \omega), \omega \in \Omega$ is said to be the cross section of the stochastic process, while the function $\eta(t, \cdot), t \in J$ is said to be the trajectory of the stochastic process. The stochastic process $\eta=\eta(t, \omega)$ is said to be continuous if a.s. (almost sure), i.e. for a.a. (almost all) $\omega_{0} \in \Sigma$, the trajectories $\eta=\eta\left(t, \omega_{0}\right)$ are continuous functions. The set $\eta=\eta(t, \omega)$ of continuous stochastic processes forms a Banach space $\mathbf{C}_{\mathfrak{L}_{2}}$ with the norm $\|\eta\|_{\mathbf{C}_{2}}=\sup _{t \in J}(D \eta(t, \omega))^{\frac{1}{2}}$.

Consider the stochastic process $\eta \in \mathbf{C L}_{2}$. By the Nelson - Gliklikh derivative of the stochastic process $\eta$ at the point $t \in J$ we mean the random variable

$$
\stackrel{\circ}{\eta}=\frac{1}{2}\left(\lim _{\Delta t \mapsto 0+} M_{t}^{\eta}\left(\frac{\eta(t+\Delta t, \cdot)-\eta(t, \cdot)}{\Delta t}\right)+\lim _{\Delta t \mapsto 0+} M_{t}^{\eta}\left(\frac{\eta(t-\Delta t, \cdot)-\eta(t, \cdot)}{\Delta t}\right)\right),
$$

if the limit exists in the sense of an uniform metric on $t \in J$. Here $M_{t}^{\eta}$ is the mathematical expectation on a subalgebra of $\Sigma$, which is generated by a random variable $\eta=\eta(t, \omega)$. If the Nelson - Gliklikh derivatives $\stackrel{\circ}{\eta}(\cdot, \omega)$ of the stochastic process $\eta$ exist at a.a. points of the interval $J$, then we say that there exists the Nelson - Gliklikh derivative $\stackrel{\circ}{\eta}(\cdot, \omega)$ a.s. on $J$. The set of continuous stochastic processes having continuous Nelson - Gliklikh derivatives $\stackrel{\circ}{\eta}$ form a Banach space $\mathbf{C}^{\mathbf{1}} \mathfrak{L}_{\mathbf{2}}$ with the norm $\|\eta\|_{\mathbf{C}^{1} \mathfrak{L}_{2}}=\sup _{t \in J}(D \eta(t, \omega)+D \stackrel{\circ}{\eta}$ $(t, \omega))^{\frac{1}{2}}$. Further, by induction, we obtain Banach spaces $\mathbf{C}^{\mathbf{l}} \mathfrak{L}_{\mathbf{2}}, \mathbf{l} \in \mathbb{N}$ of the stochastic processes having continuous Nelson - Gliklikh derivatives up to the order $\mathbf{l} \in \mathbb{N}$ inclusive on $J$. The norms in the spaces are given by the formula $\|\eta\|_{\mathbf{C}^{1} \mathfrak{L}_{2}}=\sup _{t \in J}\left(\sum_{k=0}^{1} D \eta^{(k)}(t, \omega)\right)^{\frac{1}{2}}$, where $\stackrel{\circ}{\eta}^{(0)}(t, \omega)=\eta(t, \omega)$. 


\section{Relatively Sectorial Operators and Resolving Semigroups}

Let $\mathfrak{U}$ and $\mathfrak{F}$ be real separable Hilbert spaces, $\mathcal{L}(\mathfrak{U} ; \mathfrak{F})$ be the space of linear bounded operators, and $C l(\mathfrak{U} ; \mathfrak{F})$ be the space of linear closed and densely defined operators. Construct the Hilbert spaces $\mathbf{U}_{\mathbf{K}} \mathfrak{L}_{\mathbf{2}}$ and $\mathbf{F}_{\mathbf{K}} \mathfrak{L}_{\mathbf{2}}$, where $\mathbf{K}=\left\{\lambda_{k}\right\} \subset \mathcal{R}$ is a monotone sequence such that $\sum_{k=1}^{\infty} \lambda_{k}^{2}<+\infty$. The stochastic Sobolev type equation

$$
L \stackrel{\circ}{\eta}=M \eta+N(\eta)
$$

can be reduced to two equations of the form

$$
A \stackrel{\circ}{\nu}=B \nu .
$$

Lemma 1. The following statements are true:

i) the operator $A \in \mathcal{L}(\mathfrak{U} ; \mathfrak{F})$ exactly when $A \in \mathcal{L}\left(\mathbf{U}_{\mathbf{K}} \mathfrak{L}_{\mathbf{2}} ; \mathbf{F}_{\mathbf{K}} \mathfrak{L}_{\mathbf{2}}\right)$;

ii) the operator $B \in C l(\mathfrak{U} ; \mathfrak{F})$ exactly when $B \in C l\left(\mathbf{U}_{\mathbf{K}} \mathfrak{L}_{\mathbf{2}} ; \mathbf{F}_{\mathbf{K}} \mathfrak{L}_{\mathbf{2}}\right)$.

Definition 1. The operator $M \in C l\left(\mathbf{U}_{\mathbf{K}} \mathfrak{L}_{\mathbf{2}} ; \mathbf{F}_{\mathbf{K}} \mathfrak{L}_{\mathbf{2}}\right)$ is said to be $p$-sectorial with respect to the operator $L \in \mathcal{L}\left(\mathbf{U}_{\mathbf{K}} \mathfrak{L}_{\mathbf{2}} ; \mathbf{F}_{\mathbf{K}} \mathfrak{L}_{\mathbf{2}}\right)$ (for shortness, $(L, p)$-sectorial), $p \in\{0\} \cup \mathbb{N}$, if

i) there exist constants $\alpha \in \mathcal{R}$ and $\Theta \in\left(\frac{\pi}{2}, \pi\right)$ such that the sector $S_{\alpha, \Theta}^{L}(M)=\{\mu \in$ $\mathbb{C}:|\arg (\mu-\alpha)|<\Theta, \mu \neq \alpha\} \subset \rho^{L}(M)$;

ii) there exists a constant $K_{1}>0$ such that $\max \left\{\left\|R_{(\mu, p)}^{L}(M)\right\|_{\mathfrak{U}},\left\|L_{(\mu, p)}^{L}(M)\right\|_{\mathfrak{F}}\right\}<$ $\frac{K_{1}}{\prod_{q=0}^{p}\left|\mu_{q}-\alpha\right|}$ for any $\mu_{0}, \mu_{1}, \ldots, \mu_{q} \in S_{\alpha, \Theta}^{L}(M)$.

Here $\rho^{L}(M)=\left\{\mu \in \mathbb{C}:(\mu L-M)^{-1} \in \mathcal{L}(\mathfrak{F} ; \mathfrak{U})\right\}$ is the $L$-resolvent set, and $\sigma^{L}(M)=$ $\mathbb{C} \backslash \rho^{L}(M)$ is the $L$-spectrum of the operator $M$. For $\mu_{q} \in \rho^{L}(M), q=0,1, \ldots, p$, the operator functions $R_{\mu}^{L}(M)=(\mu L-M)^{-1} L$ and $L_{\mu}^{L}(M)=L(\mu L-M)^{-1}$ are called the right $L$-resolvent and the left $L$-resolvent of the operator $M$, and $R_{(\mu, p)}^{L}(M)=\prod_{q=0} p\left(\mu_{q} L-M\right)^{-1} L$ and $L_{(\mu, p)}^{L}(M)=\prod_{q=0} p L(\mu L-M)^{-1}$ are called the right $(L, p)$-resolvent and the left $(L, p)$ resolvent of the operator.

Theorem 1. [1] Let the operator $M$ be $(L, p)$-sectorial, then there exist

$$
U^{t}=\frac{1}{2 \pi i} \int_{\gamma} R_{\mu}^{L}(M) e^{\mu t} d \mu, F^{t}=\frac{1}{2 \pi i} \int_{\gamma} L_{\mu}^{L}(M) e^{\mu t} d \mu \quad t \in \mathbb{R},
$$

which are holomorphic and uniformly bounded operator semigroups, where the contour $\Gamma \subset \rho^{L}(M):|\arg \mu| \mapsto \Theta$ for $\mu \mapsto+\infty, t \geq 0$.

The set $\operatorname{ker} V^{*}=\left\{\nu \in \mathbf{U}_{\mathbf{K}} \mathfrak{L}_{\mathbf{2}}\left(\mathbf{F}_{\mathbf{K}} \mathfrak{L}_{\mathbf{2}}\right): V^{t} \nu=0\right\}$ is said to be the kernel, the set $\operatorname{im} V^{*}=\left\{\nu \in \mathbf{U}_{\mathbf{K}} \mathfrak{L}_{\mathbf{2}}\left(\mathbf{F}_{\mathbf{K}} \mathfrak{L}_{\mathbf{2}}\right) \lim _{t \mapsto 0+} V^{t} \nu=\nu_{0}\right\}$ is said to be the image of the analytic semigroup $V^{t}: t \geq 0$. Denote $\mathfrak{U}^{1}=\left\{\mathbf{U}_{\mathbf{K}}^{1} \mathfrak{L}_{\mathbf{2}}\right\}\left(\mathfrak{F}^{1}=\left\{\mathbf{F}_{\mathbf{K}}^{\mathbf{1}} \mathbf{L}_{\mathbf{2}}\right\}\right)$, which form a closure $\operatorname{im} R_{(\mu, p)}^{L}(M)\left(\operatorname{im} L_{(\mu, p)}^{L}(M)\right)$ in the norm of the space $\mathfrak{U}=\mathbf{U}_{\mathbf{K}} \mathfrak{L}_{\mathbf{2}}\left(\mathfrak{F}=\mathbf{F}_{\mathbf{K}} \mathfrak{L}_{\mathbf{2}}\right)$.

Theorem 2. [3] If the operator $M$ is $(L, p)$-sectorial, then $\operatorname{im} U^{*}=\mathbf{U}_{\mathbf{K}}^{1} \mathfrak{L}_{\mathbf{2}}$ and $\operatorname{im} F^{*}=$ $\mathbf{F}_{\mathbf{K}}^{1} \mathfrak{L}_{2}$. 
The paper [3] studies the Showalter - Sidorov problem

$$
P\left(\eta(0)-\eta_{0}\right)=0
$$

in the spaces $\mathfrak{U}=\mathbf{U}_{\mathbf{K}} \mathfrak{L}_{\mathbf{2}}\left(\mathfrak{F}=\mathbf{F}_{\mathbf{K}} \mathfrak{L}_{\mathbf{2}}\right)$, where there are representations of the form

$$
\eta(t, \cdot)=\sum_{k=0}^{+\infty} \lambda_{k} \xi_{k}(t, \cdot) \varphi_{k}
$$

Theorem 3. [3] Let the operator $M$ be $(L, p)$-sectorial, then $\forall \eta_{0} \in \mathfrak{U}^{1} \subset \mathfrak{U}$ there exists the unique solution to problem (5), (6).

\section{Differential Forms and Computational Experiments}

Consider a two-dimensional torus obtained by the direct product of two intervals $\mathbb{T}=[0,2 \pi] \times[0,2 \pi]$ as a particular case of a two-dimensional smooth compact oriented Riemannian manifold without boundary. Let us use the theory presented in Section 1 and Section 2 to define the spaces of smooth differential $q$-forms with coefficients that are stochastic $K$-processes, which belong to $\mathfrak{U}$

$$
\omega\left(t, \omega, x_{1}, x_{2}, \ldots, x_{n}\right)=\sum_{\left|i_{1}, i_{2}, \ldots, i_{q}\right|=q} \chi_{i_{1}, i_{2}, \ldots, i_{q}}\left(t, \omega, x_{1}, x_{2}, \ldots, x_{n}\right) d x_{i_{1}} \wedge d x_{i_{2}} \wedge \ldots \wedge d x_{i_{n}},
$$

where $\left|i_{1}, i_{2}, \ldots, i_{q}\right|$ is a multi-index, and, according to $(7)$, the coefficients are given by

$$
\chi_{i_{1}, i_{2}, \ldots, i_{q}}\left(t, \omega, x_{1}, x_{2}, \ldots, x_{n}\right)=\sum_{k=1}^{\infty} \lambda_{k} \xi_{k, i_{1}, i_{2}, \ldots, i_{q}}(t) \varphi_{k} .
$$

As $\mathfrak{U}$, consider the space of differential $q$-forms defined on a smooth compact oriented Riemannian manifold without boundary and orthogonal to harmonic $q$-forms. Such spaces were constructed in [7] based on the Hodge - Kodaira theory in the deterministic case for the Cauchy problem for Dzektser equation (2). Also, consider the Showalter - Sidorov problem

$$
P\left(\eta(0)-\eta_{0}\right)=0
$$

for the stochastic version of the Dzektser equation

$$
(\lambda+\Delta) \stackrel{\circ}{\eta}=-\alpha \Delta \eta-\beta \Delta^{2} \eta
$$

moreover, the signs differ from (2), since instead of the Laplace operator we use its generalization (up to the sign) to spaces of differential forms, namely, the Laplace Beltrami operator. Denote the operators

$$
L=(\lambda+\Delta), M=-\alpha \Delta, N=\beta \Delta^{2}
$$

and arrive at (3) for $\Theta=\eta$.

For this problem, the paper [7] proves $(L, 0)$-sectoriality of the operator $M$ and constructs the relative spectrum

$$
\mu_{t}=\frac{-\alpha \lambda_{k}+\beta \lambda_{k}^{2}}{\lambda-\lambda_{k}}
$$


where $\left\{\lambda_{k}\right\}$ is the sequence of eigenvalues of the Laplace - Beltrami operator on the torus numbered in ascending order with multiplicity, and $\left\{\varphi_{k}\right\}$ is the sequence of eigenfunctions, respectively.

Introduce a grid on the torus and construct a difference analog of the trajectories of the stochastic Dzektser equation and implement the Petrov - Galerkin method in the Maple system.

To this end, we implement the following algorithm.

Step 1. Enter the parameters of the Dzektser equation $(\alpha, \beta \in \mathbb{R}, \lambda \neq 0)$.

Step 2. Construct a grid on the two-dimensional torus $\mathbb{T}$.

Step 3. Calculate eigenvalues and construct eigenfunctions.

Step 4. Present solutions in the form of an expansion in eigenfunctions.

Step 5. Obtain a numerical solution to the problem with a random value from the probability space $\Omega$.

Step 6. Obtain and display a graphical representation of the solution.

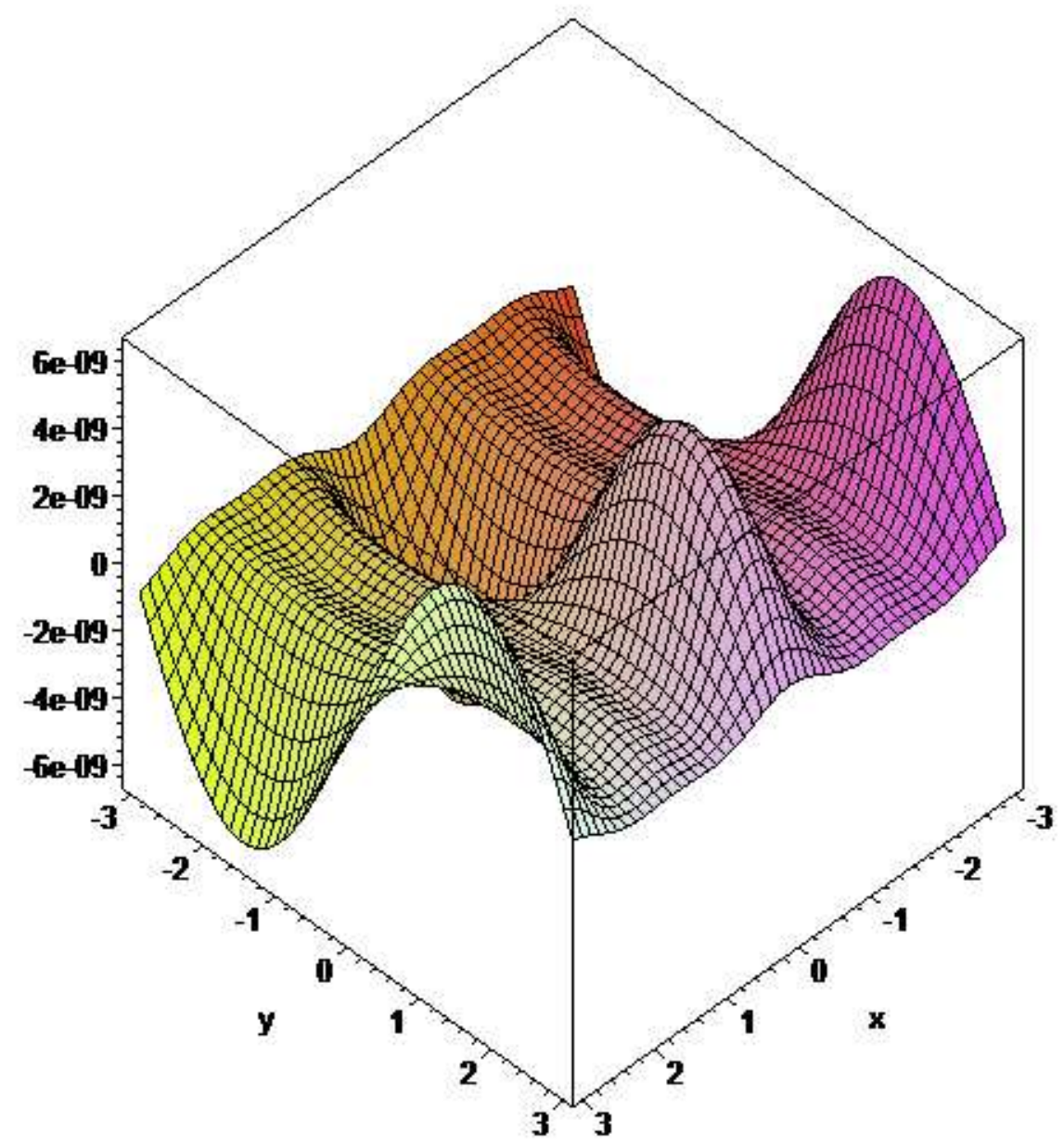

Fig. 1. Solution to (9), (10) for $\alpha=-0,5, \beta=1, \lambda=4$ at the moment $t=1$

Fig. 1 shows the solution to the inhomogeneous Dzektser equation (10) with condition (9) for the values $\alpha=-0.5, \beta=1, \lambda=4$. 
Fig. 2 shows the solution to the homogeneous Dzektser equation (10) with condition (9) for the values $\alpha=-2, \beta=-2, \lambda=0,1$.

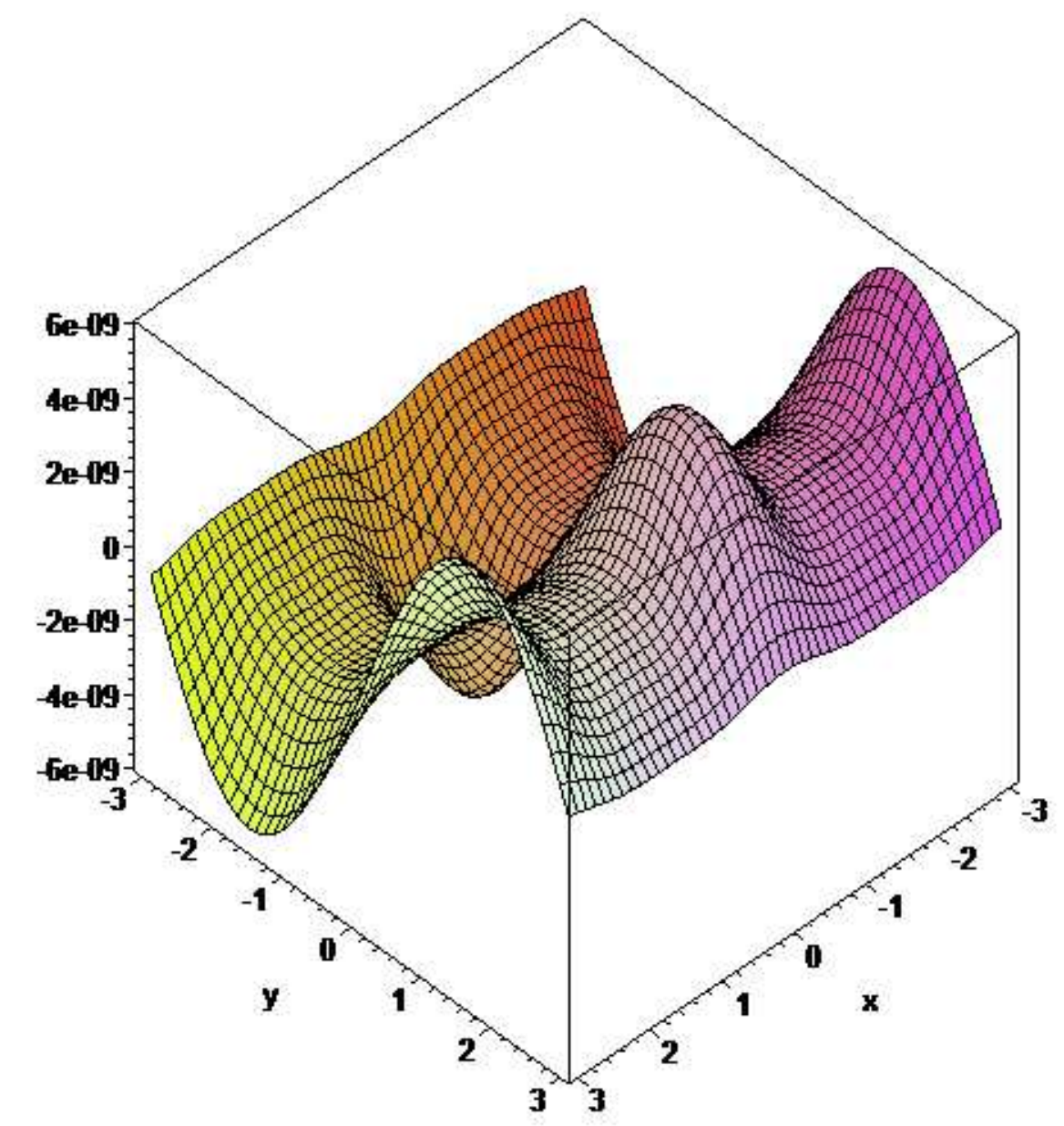

Fig. 2. Solution to (9), (10) for $\alpha=-2, \beta=-2, \lambda=0,1$ at the moment $t=1$

\section{Conclusion}

As a result of the study of numerical solutions to the homogeneous equation of the free surface of the filtered fluid, we obtain graphs of solutions for two model cases on the torus. Further, we intend to expand the base of computational experiments and continue research for Sobolev type equations with relatively radial operators.

\section{References}

1. Sviridyuk G. A. On the General Theory of Operator Semigroups. Russian Mathematics. Surveys, 1994, vol. 49, no. 4, pp. 45-74.

2. Shafranov D. E. [On the Cauchy Problem for the Equation of Free Surface of Filtred Fluid on the Manifolds]. Bulletin of the South Ural State University. Ser. Mathematical Modeling, Programming and Computer Software, 2008, no. 27 (2), pp. 117-120. (in Russian) 
3. Favini A., Sviridiuk G. A., Manakova N. A. Linear Sobolev Type Equations with Relatively p-Sectorial Operators in Space of "Noises". Abstract and Applied Analysis, 2015, vol. 2015, Article ID 697410. DOI: 10.11552015697410

4. Gliklikh Yu. E., Mohammed S. E. A. Stochastic Delay Equations and Inclusions with Mean Derivatives on Riemannian Manifolds. Global and Stochastic Analysis, 2014, vol. 1, no. 1, pp. 49-56.

5. Kitaeva O. G., Shafranov D. E., Sviridyuk G. A. Exponential Dichotomies in Barenblatt - Zheltov - Kochina Model in Spaces of Differential Forms with "Noise". Bulletin of the South Ural State University. Ser. Mathematical Modeling, Programming and Computer Software, 2019, vol. 12, no. 2, pp. 47-57. DOI: 10.14529/mmp190204

6. Shafranov D. E. Numerical Solution of the Barenblatt - Zheltov - Kochina Equation with Additive "White Noise" in Spaces of Differential Forms on a Torus Journal of Computation and Engineering Mathematics, 2019, vol. 6, no. 4, pp. 31-43. doi:10.14529/jcem190403

7. Shafranov D. E., Shvedchikova A. I. The Hoff Equation as a Model of Elastic Shell. Bulletin of the South Ural State University. Ser. Mathematical Modeling, Programming and Computer Software, 2012, no. 18 (12), pp. 47-57. (in Russian)

Dmitriy E. Shafranov, PhD (Math), Associate Professor, Department of Mathematical Physics Equations, South Ural State University (Chelyabinsk, Russian Federation), shafranovdea@susu.ru.

Received May 29, 2020

УДК 517.9

DOI: $10.14529 /$ jcem200206

\title{
ЧИСЛЕННОЕ РЕШЕНИЕ УРАВНЕНИЯ ДЗЕКЦЕРА С "БЕЛЫМ ШУМОМ"В ПРОСТРАНСТВЕ ГЛАДКИХ ДИФФЕРЕНЦИАЛЬНЫХ ФОРМ, ОПРЕДЕЛЕННЫХ HA TOPE
}

\section{Д. Е. Шафранов}

\begin{abstract}
Приведены численные решения задачи Коши для уравнения Дзекцера в недетерминированном случае в пространстве дифференциальных форм на двумерном торе. На основе ранее полученных автором решений для детерминированного случае и , в соавторстве с другими, абстрактного перехода в случае относительно секториальных операторов от детерминированных уравнений соболевского типа к недетерминированным в пространстве дифференциальных форм определенных на римановых многообразиях без края, построены траектории решения задачи Коши для уравнения Хоффа в пространствах дифференциальных форм с коэффициентами являющимися винеровскими стохастическими процессами. Так как эти процессы недифференцируемы в обычно смысле, то производная берется в смысле Нельсона-Гликлиха, а вместо оператора Лапласа на дифференциальных формах используется оператор Лапласа-Бельтрами.

Ключевые слова: уравнения соболевского типа; относительно секториальный оператор; дифференииальные формы, производная Нельсона-Гликлиха; оператор Лапласа-Бельтрами.
\end{abstract}




\section{Литература}

1. Свиридюк, Г. А. К общей теории полугрупп операторов / Г. А. Свиридюк // Успехи математических наук. - 1994. - Т. 49, № 4. - С. 47-74.

2. Шафранов, Д. Е. О задаче Коши для уравнения свободной поверхности фильтрующейся жидкости на многообразии / Д. Е. Шафранов // Вестник ЮУрГУ. Серия: Математическое моделирование и программирование. - 2008. - № 27 (2). C. $117-120$.

3. Favini A., Sviridyuk G.A., Manakova N.A. Linear Sobolev Type Equations with Relativly p-Sectorial Operators in Space of "Noises" / / Abstract and Applied Analysis. 2015. Article ID 69741. 8 p.

4. Gliklikh, Yu.E. Stochastic Delay Equations and Inclusions with Mean Derivatives on Riemannian Manifolds / Yu. E. Gliklikh, S. E. A. Mohammed // Global and Stochastic Analysis. - 2014. - V. 1, № 1, pp. 49-56.

5. Китаева, О. Г. Экспоненциальные дихотомии в модели Баренблатта - Желтова Кочиной в пространствах дифференциальных форм с "шумами" / О. Г. Китаева, Д. Е. Шафранов, Г. А. Свиридюк // Вестник ЮУрГУ. Серия: Математическое моделирование и программирование. - 2019. - Т. 12, № 2. - С. 47-57.

6. Shafranov, D. E. Numerical Solution of the Barenblatt - Zheltov - Kochina Equation with Additive "White Noise" in Spaces of Differential Forms on a Torus / D. E. Shafranov // Journal of Computation and Engineering Mathematics. - 2019. V. 6, № 4. - P. 31-43.

7. Шафранов, Д. Е. Уравнение Хоффа как модель упругой оболочки / Д. Е. Шафранов, А. И. Шведчикова // Вестник ЮУрГУ. Серия: Математическое моделирование и программирование. - 2012. - № 18 (12). - С. 77-81.

Шафранов Дмитрий Евгенъевич, кандидат физико-математических наук, доцент, доцент кафедрь уравнений математической физики, ЮжноУральский государственный университет (г. Челябинск, Российская Федерачия), shafranovde@susu.ru. 